\title{
Hirsutismo. Un problema estético en Adolescentes
}

\author{
Álvaro Peña Irúnª, Ana González Santamaría ${ }^{b}$, \\ Ana Cavadas Lópezc ${ }^{c}$ Rafael García Espinosac
}

\begin{abstract}
a Médico de Familia, C.S. Sardinero, Santander (Cantabria).

${ }^{\mathrm{b}}$ Médico de Familia, Servicio Cántabro de Salud (Cantabria).

${ }^{c}$ Residente de Medicina Familiar y Comunitaria.

Correspondencia: Álvaro Peña Irún, $B^{\circ}$ El Hondal D12, n 34, Polanco 39313 Cantabria. Correo electrónico: alvaro290475@hotmail.com.

Recibido el 15 de septiembre de 2011.
\end{abstract}

Aceptado para su publicación el 13 de octubre de 2011.

\begin{abstract}
RESUMEN
El hirsutismo tiene una prevalencia del $8 \%$ en mujeres en edad reproductiva, con importante repercusión estética en algunos casos. La historia y el examen físico son de vital importancia para la aproximación diagnóstica de estas pacientes. Nuestro reto, además de identificar aquellos casos con enfermedades subyacentes graves, es proporcionar un tratamiento lo más eficaz posible para evitar problemas psicológicos.

Palabras claves: Síndrome del Ovario Poliquístico, Hirsutismo, Hiperandrogenismo.
\end{abstract}

\section{ABSTRACT}

Hirsutism. An esthetic problem in Adolescents.

Hirsutism has a prevalence of $8 \%$ in women of reproductive age, with significant esthetic repercussions in some cases. History and physical examination are of vital importance in the diagnostic work-up of these patients. Our challenge, in addition to identifying those cases with serious underlying disease, is to provide the most effective treatment possible to prevent psychological problems.

Key words: Polycistic Ovary Syndrome, Hirsutism, Hyperandrogenism.

\section{INTRODUCCIÓN}

El hirsutismo se define como un exceso de vello con patrón masculino, de aparición en mujeres ${ }^{1}$. Lo debemos diferenciar de hipertricosis, que es el crecimiento exagerado del vello distribuido sin un patrón sexual definido. Es totalmente dependiente de andrógenos, bien por sobreproducción de los mismos o por un aumento de sensibilidad del folículo piloso a la hormona.

Según la escala de Ferriman-Gallwey², que otorga una puntuación de 0 a 4 en 9 áreas corporales, es definido por un score mayor de 8.

En cuanto a su etiología, lo más frecuente es el síndrome de ovario poliquístico (SOP) y, dado que la mayoría de las pacientes con hirsutismo presentan SOP o hirsutismo idiopático ( $80 \%-90 \%)$, el problema es identificar el pequeño número de pacientes en que obedece a otras causas, fundamentalmente tumores productores de andrógenos.

\section{OBSERVACIONES CLÍNICAS}

Presentamos el caso de una mujer de 15 años con menarquía a los 12 años y menstruaciones irregulares sin tratamiento farmacológico habitual ni otros antecedentes de interés. Consulta porque desde hace un año nota aumento del vello facial, así como también en brazos, hombros, piernas y región periumbilical, determinando un score de 14 puntos (Figura 1). Ha intentado usar algún producto cosmético e incluso afeitado sin buen resultado estético. 
Asocia acné vulgar. No parece presentar cambio de voz o aumento de la masa muscular, como tampoco refiere caída del cabello. A la exploración conserva un buen estado general, cierto sobrepeso (Índice masa corporal de 29), sin hábito cushingoide. La auscultación cardiopulmonar era normal, no tenía organomegalias y no presentaba alteraciones en genitales.

Se le realizó una analítica completa siendo el hemograma normal (hemoglobina 13,7 gr/dl, 6.900 leucocitos y 244.000 plaquetas), velocidad de sedimentación globular de 24 y bioquímica con parámetros normales. Se le pidió una analítica hormonal en la que todos los valores se hallaban dentro de la normalidad: hormona luteinizante (LH) 5,1 UI/l, hormona folículoestimulante (FSH) 4,4 $\mathrm{UI} / \mathrm{I}$, 17betaestradiol 13,8 UI/I, progesterona 0,71 $\mathrm{UI} / \mathrm{l}$, dehidroepiandrosterona (DHEA) $200 \mathrm{mcg} / \mathrm{dl}$, testosterona $45 \mathrm{ng} / \mathrm{dl}$, prolactina $20 \mathrm{UI} / \mathrm{l}$ y tirotropina (TSH) $3 \mathrm{UI} / \mathrm{I}$.

Dada la presencia de signos clínicos de hiperandrogenismo (hirsutismo y acné), la historia de menstruación irregular y haber descartado otras causas de virilización, realizamos el diagnóstico de síndrome de ovario poliquístico. Solicitamos una ecografía ovárica que, aunque no imprescindible para el diagnóstico, fue compatible con dicha patología e iniciamos tratamiento con etinilestradiol más acetato de ciproterona, evaluando a la paciente a los 6 meses con notable mejoría.

\section{COMENTARIOS}

La causa más frecuente de hirsutismo es el SOP. Otras causas son infrecuentes, como la hiperplasia adrenal congénita debido a déficit de 21 alfahidroxilasa, tumores secretores de andrógenos (ováricos o suprarrenales) además de hiperprolactinemia, síndrome de Cushing, acromegalia y disfunción tiroidea, que también deben ser considerados ${ }^{3}$. No debemos olvidar el consumo de fármacos con acción androgénica.

Lo primordial es descartar tumores productores de andrógenos, y en este sentido son varios los hallazgos que sugieren esta etiología ${ }^{1}$ :

- Comienzo abrupto, curso rápido y empeoramiento progresivo.

- Inicio en la tercera década de la vida o más tarde, en lugar de próximo a la pubertad.

- Signos de virilización: alteración de la voz, clitoromegalia, alopecia, aumento de la masa muscular.

\section{- Determinación de valores hormonales ${ }^{7}$. Testosterona mayor de $150 \mathrm{ng} / \mathrm{dl}$ o DHEA mayor de $700 \mathrm{mcg} / \mathrm{dl}$.}

No a todas las mujeres se les debe solicitar análisis de laboratorio. Sólo se recomienda en casos de hirsutismo moderado/severo o de cualquier grado si hay datos de riesgo para presentar tumores subyacentes. En general se recomienda medir la testosterona total y la DHEA, y si además hay irregularidades menstruales la prolactina. Otros test adicionales $(17 \mathrm{OH}$ progesterona, $\mathrm{LH}, \mathrm{FSH} 0$ supresión con dexametasona) sólo si hay sospecha de otras patologías.

Según el NIH consensus criterio podemos diagnosticar de $\mathrm{SOP}^{5}$ ante la presencia de irregularidades menstruales (menos de 9 menstruaciones al año), evidencia de hiperandrogenismo (clínico o bioquímico) y la exclusión de otras causas de exceso hormonal. Por tanto, la ecografía ovárica no es completamente necesaria, ya que la apariencia poliquística no es específica de SOP.

Del 50 al $90 \%$ de estos pacientes tienen los andrógenos séricos elevados, pero pueden presentar valores normales como es el caso de nuestra paciente. La diferencia fundamental con el hirsutismo idiopático es que éste carece de alteraciones menstruales, teniendo el SOP cierta agregación familiar.

En cuanto al tratamiento, inicialmente se recomiendan medidas cosméticas (cremas, fotodepilación, etc.). Si estas son insuficientes, se pautará tratamiento farmacológico. Los distintos estudios sugieren comenzar con anticonceptivos orales (ACO) compuestos de una combinación de estrógenos y progestágenos, sin aconsejar ninguno en especial, pero sí evitar el levonorgestrel como progestágeno porque tiene acción androgénica. Se recomienda formulaciones de 30-35 microgramos de etinilestradiol, dejando las dosis más bajas (20 $\mathrm{mcg})^{6}$ para mujeres de mayor edad (por encima de los 40 años). En el $60 \%$ de los casos se reduce considerablemente el hirsutismo. No es necesario monitorizar los niveles de andrógenos durante el tratamiento salvo que progrese la enfermedad a pesar de la terapia.

El mecanismo por el cual los ACO disminuyen los andrógenos es por inhibición de la $\mathrm{LH}$ y por lo tanto de los andrógenos dependientes de esta hormona (estímulo de la síntesis hepática de proteínas 
ligadoras de andrógenos que da lugar a una disminución de la testosterona libre e inhibición de la secreción adrenal de andrógenos ${ }^{4}$ ).

Los antiandrógenos en monoterapia (ciproterona o espironolactona), aunque eficaces, no están recomendados por sus efectos perjudiciales sobre el feto (feminización fetal), pero se pueden administrar asociados a un anticonceptivo. La mejoría no es objetivable hasta transcurridos 6 meses, que es aproximadamente la vida media del folículo, por lo que no se debe hacer ninguna modificación del tratamiento hasta entonces. Debemos continuar toda la edad reproductiva, interrumpiéndolo en caso de deseo de gestación.

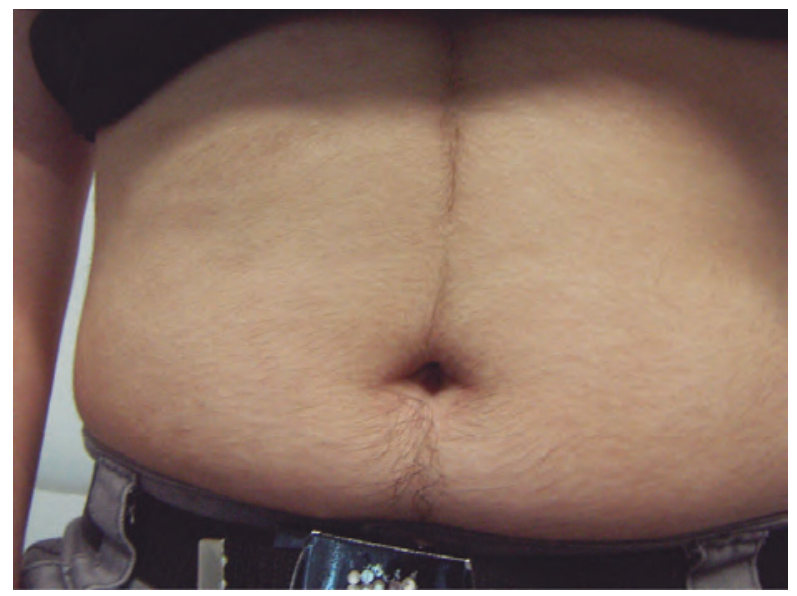

Figura 1. Aumento de vello en región periumbilical.

\section{BIBLIOGRAFÍA}

1. Rosenfield RL. Clinical practise. Hirsutism. N Engl J Med. 2005; 353:2578-88.

2. Hach $\mathrm{R}$ et al. Ferriman-Gallwey hirsutism scoring system. Am J Obste Gynecol. 1981. 140: 815-830

3. Martin KA, Chang RJ, Ehrmann DA, Ibanez L, Lobo RA, Rosenfield RL, et al. Swiglo Evaluation and treatment of hirsutism in premenopausal women: An Endocrine Society Clinical Practice Guideline. J Clin Endocrinol Metab. 2008, 93:1105-20

4. Zouboulis CC, Chen WC, Thornton MJ, Qin K, Rosenfield R. Sexual hormones in human skin. Horm Metab Res. 2007; 39:85-95.
5. Zawadzki JK, Dunaif A. Diagnostic criteria for polycystic ovary syndrome. Towards a rational approach. In: Dunaif A, Givens JR, Haseltine FP, Merriam GR, eds. Polycystic ovary syndrome. Endocrinology and metabolism. Boston: Blackwell, 1992. p. 337-384.

6. Koulouri O, Conway CS. Management of hirsutism. BMJ. 2009; 338:847.

7. Friedman $\mathrm{Cl}$, Schmidt GE, Kim MH, Powell J. Serum testosterone concentrations in the evaluation of androgenproducing tumors. Am J Obstet Gynecol. 1985; 153:44. 